
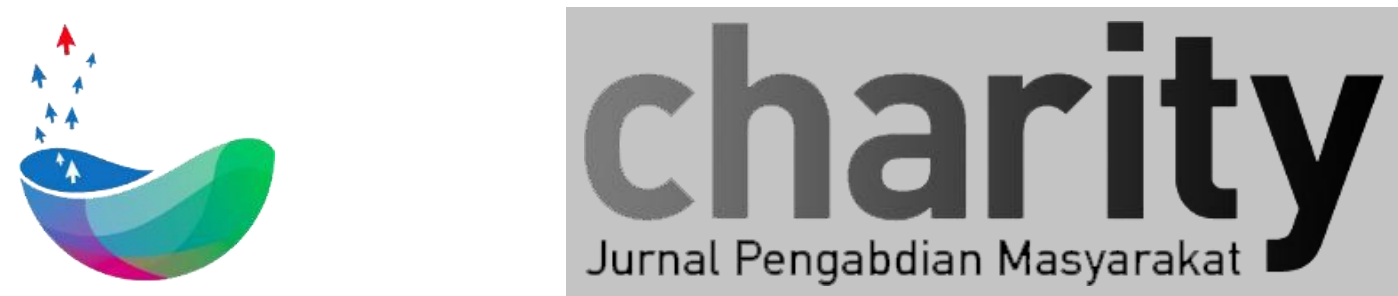

\title{
STRATEGI LOW COST DIGITAL MARKETING DI MASA PANDEMI BERSAMA UMKM KECAMATAN BOJONGLOA KIDUL KOTA BANDUNG
}

\author{
Faisal Reza ${ }^{1}$, Yanuar Ilham ${ }^{2}$, Nisa Lathifah ${ }^{3}$, Hanafi $^{4}$, Divan Fadhila ${ }^{5}$ \\ ${ }^{1}$ Program Studi Ilmu Komunikasi, Fakultas Komunikasi dan Desain, Universitas Informatika dan Bisnis Indonesia \\ ${ }^{2}$ Program Studi Ilmu Komunikasi, Fakultas Komunikasi dan Desain, Universitas Informatika dan Bisnis Indonesia \\ Program Studi Ilmu Komunikasi, Fakultas Komunikasi dan Desain, Universitas Informatika dan Bisnis Indonesia \\ Program Studi Ilmu Komunikasi, Fakultas Komunikasi dan Desain, Universitas Informatika dan Bisnis Indonesia \\ Program Studi Ilmu Komunikasi, Fakultas Komunikasi dan Desain, Universitas Informatika dan Bisnis Indonesia \\ * ezafaisal@gmail.com, yanuarilham@unibi.ac.id,nisalathifah@unibi.ac.id, hn.hanafi@unibi.ac.id, divanfadhila@gmail.com
}

\section{INFO ARTIKEL}

Diterima 16 September 2021

Direvisi 27 Oktober 2021

Disetujui 15 November 2021

Tersedia Online 20 November 2021

Keyword: UMKM, digital marketing, strategi low cost.

\begin{abstract}
ABSTRAK
Tujuan dari pelaksanaan program pengabdian kepada masyarakat ini adalah untuk melaksanakan "Pelatihan Strategi Low Cost Digital Marketing di Masa Pandemi Bersama UMKM di Kecamatan Bojongloa Kidul Kota Bandung" agar menambah pengetahuan, keterampilan dan pengalaman bagi para peserta dalam dunia bisnis secara online. Target khusus kami yaitu kepada para peserta pelatihan diharapkan dapat memiliki pengetahuan serta keterampilan bisnis pemasaran dengan mengolaborasikan teknologi secara digital atau online sebagai Langkah untuk menjalankan pemasaran selama masa Pandemi Covid-19 yang menerapkan adaptasi kebiasaan baru. Dengan kecanggihan teknologi saat ini, yang memudahkan para UMKM untuk merambah pemasaran di bidang digital. Kehadiran berbagai macam marketplace seperti Shopee, Tokopedia, Lazada, Bukalapak dan lain sebagainya, menjadi angin segar untuk para pelaku usaha saat ini. Tidak hanya itu perkembangan media social saat ini yang tidak lagi hanya sebagai platform untuk berjejaring atau mencari teman saja, kini media sosial pun sudah menjadi platform pemasaran yang banyak diminati tidak hanya bagi para pelaku usaha tetapi juga para pengguna media social itu sendiri/konsumen. Contohnya, saat ini platform media social Instagram memiliki fitur khusus untuk para akun bisnis untuk membuat "toko online" dalam bentuk katalog bisnis.

Dengan melihat fenomena tersebut dibutuhkan pengetahuan dan keterampilan yang baik dalam menunjang pemasaran melalui digital. Salah satunya adalah keterampilan dalam memilih media digital yang tepat untuk membidik segmentasi, keterampilan dalam membuat suatu naskah iklan yang baik, serta keterampilan dalam membuat suatu konten pemasaran yang baik dalam platform digital. Kegiatan pelatihan ini akan berlangsung selama 1 hari. Luaran dari kegiatan ini berupa peningkatan pengetahuan dan keterampilan tentang strategi pemasaran dengan menggunakan media digital bagi peserta dan artikel ilmiah pada jurnal pengabdian kepada masyarakat.
\end{abstract}


Korespondensi:

Lembaga Penelitian dan Pengabdian Masyarakat, Universitas Informatika dan Bisnis Indonesia

Jl. Soekarno Hatta No 643 Bandung 40286 Indonesia

E-mail : lppm@unibi.ac.id

ORCID ID: https://orcid.org/0000-0001-7769-1266

Penulis Pertama: Faisal Reza

https:// 10.25124/charity.v4i2a

Paper_reg_number xxx @ The Authors. Published by Directorate of Research and Community Service, Telkom University.

This is an open access article under the xxx license (https://creativecommons.org/licenses/xxx)

\section{Bab I Pendahuluan}

\section{Latar Belakang}

UMKM merupakan usaha perdagangan yang dikelola badan usaha atau perorangan yang merujuk pada usaha ekonomi produktif sesuai dengan kriteria yang diterapkan Undang-Undang Nomor 20 Tahun 2008. UMKM merupakan kelompok usaha yang terbukti tahan menghadapi berbagai goncangan krisis ekonomi. Hal ini terjadi karena kemudahan dalam UMKM mengadopsi inovasi dalam bisnis.

Menurut Philip Kotler, pemasaran adalah suatu proses sosial dan manejerial yang di dalamnya kelompok dan individu mendapatkan apa yang mereka inginkan dan butuhkan dengan menciptakan, menawarkan, dan mempertukarkan produk yang bernilai dengan pihak lainnya. Secara sederhana, pemasaran lebih identik dengan proses pengenalan produk atau layanan kepada konsumen yang potensial. Pemasaran merupakan suatu konsep yang menyangkut suatu sikap mental, suatu cara berpikir yang membimbing pelaku unutuk melakukan sesuatu yang tidak selalu menjual benda tetapi juga menjual gagasan-gagasan, karir, tempat (pariwisata, rumah, lokasi industri), undang-undang, jasa (pengangkutan, penerbangan, pemotongan rambut, kesehatan), hiburan (pertunjukan, pertandingan), dan kegiatan-kegiatan nirlaba seperti yayasan-yayasan sosial dan keagamaan [1].

Dalam hal ini, pengelola pemasaran harus menyadari adnya saling ketergantungan diantara sejumlah kegiatan, misalnya antara kegiatan penjualan dan promosi, agar dapat tercapai pemasaran yang efektif [2]. Periklanan dan promosi memiliki peran penting dalam proses pemasaran, yaitu dengan menginformasikan konsumen mengenai barang atau jasa itu dalam memuaskan kebutuhan atau keinginan mereka [3].

Aspek-aspek dalam pemasaran meliputi periklanan, public relations, promosi, distribusi, penjualan, dan pelayanan konsumen. Terdapat beberapa jenis strategi pemasaran yang sering digunakan, diantaranya iklan berbayar, pemasaran transaksional, pemasaran media sosial, pemasaran interaktif, pemasaran konten, search engine optimization, telemarketing, email marketing.

Perencanaan media harus mempertimbangkan secara cermat karakteristik dari masing-masing media tersebut, begitu pula faktor lainnya. Perencanaan media yang baik akan menghasilkan komunikasi yang efektif sehingga pesan yang disampaikan mendapat perhatian lebih besar dari target audiensi [4]. 
Media sosial telah membawa perubahan yang luar biasa terhadap praktik komunikasi korporat. Pemasaran melalui media sosial memungkinkan perusahaan untuk berkomunikasi secara langsung dan cepat dengan konsumen.

Pandemi Covid-19 yang memberikan dampak cukup serius terntunya memberikan sebuah krisis baru dalam dunia perekonomian, khususnya UMKM yang dianggap dapat menjadi penggerak Pemulihan Ekonomi Nasional. Berbagai kebijakan dikeluarkan oleh pemerintah dalam rangka menghadapi pandemi Covid-19 ini. Berbagai penerapan Adaptasi kebiasaan baru atau disebut juga dengan New Normal diberlakukan, sehingga banyak aktifitas yang harus diterapkan dengan kebiasaan baru. Dalam penerapan ini UMKM tentunya menjadi salah satu korban yang terkena dampak.

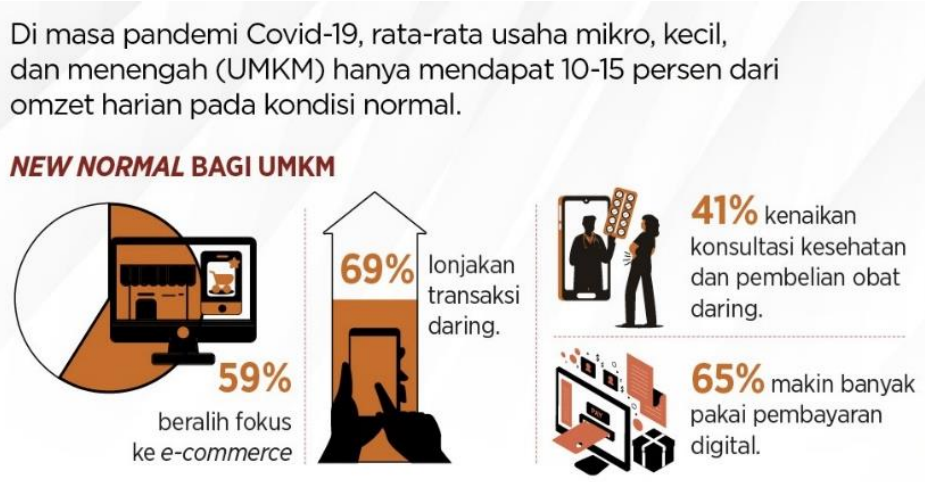

TEKNOLOGI UBAH TANTANGAN JADI KESEMPATAN

Perilaku konsumen berubah, UMKM harus manfaatkan teknologi.

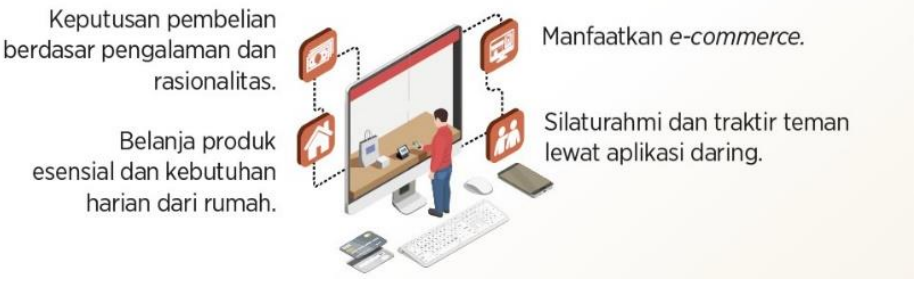

\section{Gambar: New Normal UMKM \\ Sumber: Katadata.co.id}

New Normal harus diterapkan pada segala lini termasuk pada UMKM, kondisi ini mengharuskan para pelaku UMKM untuk menyelamatkan usaha mereka dengan menerapkan Teknik-teknik pemasaran melalui dunia digital yang tentunya efektif dan minim pendanaan. Pengetahuan para UMKM terhadap pola berfikir digital tentunya harus ditanamkan agar mereka dapat bertahan di masa Pandemi yang serba sulit seperti ini. Dibutuhkan pemahaman tentang pola berpikir digital, Teknik pemasaran, serta strategi yang efektif dan minim pendanaan agar mereka dapat bersaing di dunia digital yang mulai padat akan persaingan. 


\section{Analisis Situasi}

Dunia pemasaran saat ini sudah mulai bergeser dari konvensional ke pemasaran digital (marketing digital). Apalagi dimasa pandemic Covid-19 saat ini, yang mengharuskan orang banyak melakukan aktivitas di dalam rumah dan membatasi pergerakan di luar rumah, seperti bekerja dari rumah, belajar dari rumah ibadah di rumah sampai berbelanja dari rumah. Segala aktivitas tersebut tentunya akan berjalan dengan didukung dengan perangkat dan koneksi internet.

Komunikasi pemasaran digital merupakan salah satu bagian dari kegiatan komunikasi bisnis. Komunikasi bisnis dapat dilakukan secara vrbal dan nonverbal. Komunikasi bisnis tersebut terdiri dari pendapat, ide, gagasan maupun informasi penting terkait perusahaan maupun produk dari perusahaan tersebut.

Komunikasi pemasaran digital (digital marketing) adalah strategi mengenalkan hingga memasarkan suatu produk melalui media digital yang tentunya terhubung dengan koneksi internet. Aktivitas pemasaran digital (digital marketing) kini sering kita jumpai, seperti pemasaran melalui ecommerce dan online shop melalui media sosial. Shopee dan Lazada sudah memiliki lebih dari 100 juta lebih pengguna, Tokopedia dan Bukalapak lebih dari 50 juta pengguna sampai dengan Juni 2021. Dengan kemudahan layanan serta banyaknya promo yang ditawarkan oleh setiap platform e-commerce tersebut membuat konsumen tertarik untuk berbelanja melalui platform tersebut. Dengan begitu, banyak pula para pegiat usaha seperti UMKM yang menggunakan platform tersebut sebagai media pemarasan.

Media sosial kini juga tidak lagi sebagai media untuk berteman dan media eksistensi saja. Media sosial saat ini sudah banyak dipakai untuk menunjang aktivitas promosi hingga pemasaran. Media sosial yang kini sering digunakan sebagai media pemasaran yaitu Facebook dan Instagram. Dengan adanya fitur marketplace di Facebook dan Instagram bisnis memungkinkan para pebisnis, khususnya UMKM untuk menjajakan segala produknya dengan mudah.

Agar pemasaran digital (marketing digital) yang dilakukan oleh UMKM dapat berjalan dengan maksimal, efektif dan minim pendanaan maka diperlukan keterampilan khusus untuk mengoperasikan segala fitur yang ada baik di media e-commerce maupun di media sosial bisnis.

\section{Persoalan Mitra}

Di tengah pandemik covid-19 saat ini, menuntut para pebisnis, khususnya UMKM untuk melayani konsumen secara efektif melalui platform digital. Dengan begitu para UMKM harus tetap melakukan kegiatan pemasaran digital (digital marketing). Namun biasanya masih ada pelaku UMKM yang mungkin belum memiliki pemahaman dan keterampilan dalam mengoperasikan e-commerce yang baik dan efketif serta dalam menggunakan media sosial bisnis secara tepat dan dengan konten yang menarik. 
Para akademisi Program Studi Ilmu Komunikasi UNIBI yang memiliki kekhasan dalam bidang komunikasi bisnis digital, ingin berbagi pengalaman dan pengetahuan secara teoritis maupun praktis dalam bidang pemasaran digital (digital marketing) melalui Program PKM (Pengabdian Kepada Masyarakat) kepada para pelaku UMKM khususnya di Kecamatan Bojongloa Kidul ni.

\section{Identifikasi dan Perumusan Masalah}

Melihat persoalan mitra yang perlu penanganan tersendiri dalam peningkatan pengetahuan, maka tim pengusul mengidentifikasi masalah sebagai berikut :

1. Kurangnya pemahaman UMKM dalam menggunakan fitur ecommerce/Digital Marketing dan media sosial dalam aktivitas bisnisnya secara efektif.

2. Masih banyaknya UMKM menggunakan e-commerce/Digital Marketing dan media sosial bisnis yang belum mengenal strategi komunikasi bisnis dengan pemanfaatan media digital yang efektif.

Dari identifikasi masalah tersebut, maka tim pengusul merumuskan masalah yakni peningkatan pengetahuan strategi bisnis online bagi pemula melalui media komunikasi.

\section{Tujuan Kegiatan}

Adapun tujuan kegiatan Seminar Pelatihan Strategi Low Cost Digital Marketing di Masa Pandemi Bersama UMKM di Kecamatan Bojongloa Kidul ini adalah sebagai berikut:

1. Untuk meningkatkan pemahaman pelaku UMKM mengenai fitur ecommerce dan media social yang efektif dan minim pendanaan.

2. Untuk meningkatkan pemahaman terkait strategi komunikasi bisnis dengan pemanfaatan media digital yang efektif dan minim pendanaan.

\section{Manfaat Kegiatan}

Seminar Pelatihan Strategi Low Cost Digital Marketing di Masa Pandemi Bersaama UMKM di Kecamatan Bojongloa Kidul dapat memberikan manfaat bagi para pelaku UMKM di Kecamatan Bojongloa Kidul. Adapun manfaat kegiatan tersebut antara lain:

1. Meningkatkan kemampuan pelaku UMKM di Kecamatan Bojongloa Kidul dalam penggunaan fitur-fitur pada e-commerce/Digital marketing.

2. Meningkatkan pemahaman strategi berbisnis para pelaku UMKM di Kecamatan Bojongloa Kidul melalui pemanfaatan media digital yang efektif dan minim pendanaan. 


\section{Bab II Target Luaran}

\section{Target}

Target dari pengabdian kepada masyarakat (PKM) UNIBI ini adalah meningkatkan pengetahuan dan keterampilan untuk menjalankan bisnis kepada pelaku UMKM dengan memanfaatkan media komunikasi secara online.

Tabel 2.1 Target Capaian

\begin{tabular}{|c|c|c|c|c|}
\hline No & $\begin{array}{c}\text { Jenis } \\
\text { Keterampilan }\end{array}$ & Materi Pembelajaran & Produk & Keterangan \\
\hline 1. & $\begin{array}{l}\text { Digital Mindset } \\
\text { (Pola Berpikir } \\
\text { Digital) }\end{array}$ & $\begin{array}{ll}\text { - } & \text { Pengetahuan tentang } \\
\text { perkembangan dunia } \\
\text { digital } \\
\text { - } \quad \text { Dampak Pandemi } \\
\text { Covid-19 dan } \\
\text { kaitannya dengan } \\
\text { New Normal bagi } \\
\text { UMKM }\end{array}$ & $\begin{array}{l}\text { Pengetahuan tentang } \\
\text { perkembangan dunia digital di } \\
\text { Indonesia } \\
\text { Pengetahuan dan pemahaman } \\
\text { tentang dampak pandemi } \\
\text { Covid-19 terhadap Penerapan } \\
\text { Kebiasan Baru bagi UMKM }\end{array}$ & Tangible \\
\hline 2. & $\begin{array}{l}\text { Pemanfaatan } \\
\text { fitur } e \text { - } \\
\text { commerce/Digi } \\
\text { tal Marketing } \\
\text { sebagai sarana } \\
\text { pemasaran } \\
\text { yang efektif } \\
\text { dan minim } \\
\text { pendanaan di } \\
\text { masa Pandemi }\end{array}$ & $\begin{array}{l}\text { - Pengetahuan tentang } \\
\text { media sosial dan } e \text { - } \\
\text { commerce } \\
\text { - Pengetahuan tentang } \\
\text { strategi penggunaan } \\
\text { social media } \\
\text { marketing yang } \\
\text { efektif dan minim } \\
\text { pendanaan }\end{array}$ & $\begin{array}{l}\text { Pengetahuan dan pemahaman } \\
\text { tentang media sosial } \\
\text { Pengetahuan dan pemahaman } \\
\text { tentang social media } \\
\text { marketing yang efektif selama } \\
\text { masa Pandemi /Adaptasi } \\
\text { Kebiasaan Baru }\end{array}$ & Tangible \\
\hline
\end{tabular}

\section{Luaran}

Jenis luaran yang akan dihasilkan dari program pengabdian kepada masyarakat yang dibuat ini adalah :

a. Pengetahuan

Mendapatkan pengetahuan tentang penggunaan media pemasaran digital seperti e-commerce dan media sosial dengan strategi yang efektif dan minim pendanaan.

b. Artikel Ilmiah 
Artikel ilmiah sebagai penambahan referensi kegiatan pengabdian kepada masyarakat terkait strategi pemasaran digital di jurnal pengabdian kepada masyarakat.

\section{Bab III Metode Pelaksanaan dan Evaluasi}

\section{Metode Pelaksanaan}

Dalam pelaksanaan PKM tim pelaksana melakukan beberapa tahapan yaitu:

1. Tahap 1 - Tahap Brainstorming

Pada tahap ini, tim pelaksana menggali permasalahanpermasalahan UMKM dalam menggunakan pemasaran digital (digital marketing)

2. Tahap 2 - Tahap Penyampaian Materi

Pada tahap ini dilakukan penyampaian materi mengenai : Pelatihan Strategi Low Cost Digital Marketing di Masa Pandemi.

3. Tahap 3 - Tahap Diskusi dan Tanya Jawab

Pada tahap ini, dilakukan suatu bentuk diskusi mengenai materi pelatihan yang telah disampaikan, disertai forum tanya jawab yang membuka kesempatan bagi peserta untuk menggali lebih dalam tentang materi yang disampaikan.

4. Tahap 4 - Tahap Akhir

Pada tahap ini, para peserta diberi kesempatan untuk mengevaluasi segala kegiatan mereka ketika melakukan kegiatan pemasaran terhadap bisnisnya.

\section{Langkah-langkah Pelaksanaan Kegiatan}

Adapun langkah-langkah dari penyelenggaraan Pengabdian kepada Masyarakat dengan tema Pelatihan Strategi Low Cost Digital Marketing Bersama UMKM di Kecamatan Bojongloa Kidul ini adalah sebagai berikut:

Tabel 3.2 Pelaksanaan Kegiatan

\begin{tabular}{|c|c|c|c|}
\hline 1 & $09.20-$ & $\begin{array}{c}\text { Pemutaran Film UMKM } \\
\text { Punya Cerita Karya } \\
\text { Mahasiswa Tahap I }\end{array}$ & $\begin{array}{c}\text { Pemutaran beberapa Film } \\
\text { pendek karya Mahasiswa } \\
\text { tentang UMKM di kec. } \\
\text { Bojongloa Kidul }\end{array}$ \\
\hline \multirow{2}{*}{2} & 09.40 & Penyampaian Materi oleh & $\begin{array}{c}\text { Penyampaian materi tentang } \\
\text { "Strategi Low Cost Digital } \\
\end{array}$ \\
& $09.40-$ & Narketing UMKM di Masa & Pandemi" oleh Bapak Yanuar \\
& 10.10 & & Ilham, S.Ds., M.Si. \\
\hline
\end{tabular}




\begin{tabular}{|c|c|c|c|}
\hline 3 & $\begin{array}{l}10.10- \\
10.30\end{array}$ & $\begin{array}{c}\text { Pemutaran Film UMKM } \\
\text { Punya Cerita Karya } \\
\text { Mahasiswa Tahap II }\end{array}$ & $\begin{array}{l}\text { Pemutaran beberapa Film } \\
\text { pendek karya Mahasiswa } \\
\text { tentang UMKM di kec. } \\
\text { Bojongloa Kidul }\end{array}$ \\
\hline 4 & 10.40.11.10 & $\begin{array}{c}\text { Penyampaian Materi oleh } \\
\text { Narasumber } 2\end{array}$ & $\begin{array}{c}\text { Penyampaian Materi tentang } \\
\text { Copywriting oleh Bapak Nugrah } \\
\text { Sugiarat, S.S., M.I.Kom. }\end{array}$ \\
\hline 5 & $\begin{array}{l}11.10- \\
11.40\end{array}$ & Sesi Tanya Jawab & $\begin{array}{l}\text { Peserta melontarkan pertanyaan } \\
\text { seputar pengalaman ataupun } \\
\text { keingintahuan mengenai strategi } \\
\text { digital marketing yang efektif } \\
\text { dan Kreatif Copywriting } \\
\text { kemudian pembicara menjawab } \\
\text { pertanyaan yang diberikan } \\
\text { peserta }\end{array}$ \\
\hline
\end{tabular}

\section{Evaluasi}

Evaluasi pemahaman peserta dimaksud untuk mengetahui sejauhmana tingkat pemahaman peserta terhadap materi yang telah disampaikan. Evaluasi ini dilakukan dengan menilai pemahaman peserta mengenai Digital Marketing. Adapun kriteria penilaian sebagai berikut:

- $\mathrm{A}=80 \%-100 \%$ Bagaimana peserta menggunakan Strategi Low Cost Digital Marketing di Masa Pandemi : Pemahaman tinggi.

- $\mathrm{B}=60 \%-79 \%$ Bagaimana peserta menggunakan Strategi Low Cost Digital Marketing di Masa Pandemi : Pemahaman sedang.

- $\mathrm{C}=40 \%-59 \%$ Bagaimana peserta menggunakan Strategi Low Cost Digital Marketing di Masa Pandemi : Pemahaman rendah

- $\mathrm{D}=<40 \%$ Bagaimana peserta menggunakan Strategi Low Cost Digital Marketing di Masa Pandemi : pemahaman kurang.

Berdasarkan hasil pengamatan terhadap proses kegiatan seminar Pelatihan Strategi Low Cost Digital Marketing di Masa Pandemi secara daring, Sebagian besar peserta memahami materi yang telah disampaikan dengan Nilai B (60\% - 79\% Bagaimana peserta memahami tentang Digital Marketing yang efektif dan minim pendanaan : Pemaham Sedang). Hal tersebut dinilai pada saat kegiatan tanya jawab dengan para peserta diakhir kegiatan.

Evaluasi dalam webinar ini dilakukan dengan kesempatan peserta untuk memberikan masukan pada kolom Chat Zoom. Tim penyusun mencantumkan harapan dan kesan peserta terhadap adanya kegiatan ini. Dari harapan dan kesan terlihat bahwa peserta sangat antusias terhadap Seminar Strategi Low 
Cost Digital Marketing di masa Pandemi ini dan mengharapkan untuk kedepannya agar kami bisa mengadakan kegiatan serupa kembali.

Hal ini membuktikan bahwa peserta memahami materi-materi yang pembicara bawakan dan peserta mendapatkan banyak ilmu mengenai Strategi Low Cost Digital Marketing di Masa Pandemi, khususnya dalam membuka wawasan strategi pemasaran yang efektif dan minim pendanaan selama masa Pandemi Covid-19.

\section{Bab IV Hasil dan Pembahasan}

\section{Hasil}

Berdasarkan pengamatan terhadap proses kegiatan seminar Strategi Low Cost Digital Marketing di Masa Pandemi , dapat diperoleh hasil sebagai berikut:

1. Materi yang disampaikan oleh pemateri dapat diterima dengan baik dan mendapatkan respon yang positif dilihat dari antusiasme para peserta saat kegiatan berlangsung.

2. Sebagian besar peserta menilai bahwa materi seminar tentang Strategi Low Cost Digital Marketing di Masa Pandemi sebagai sarana pemasaran di masa Pandemi Covid-19 sangat membantu untuk menggunakan media sosial dengan baik dan benar guna memasarkan produknya.

3. Dari evaluasi yang telah dilakukan, diperoleh nilai yang cukup baik untuk pemahaman materi dan keterampilan meliterasi media.

4. Kegiatan seminar Strategi Low Cost Digital Marketing di Masa Pandemi ini dapat dikatakan cukup berhasil. Ditunjukkan dengan adanya respon yang positif dari awal hingga akhir kegiatan, suasana dan antusiasme peserta saat tanya jawab cukup baik.

\section{Pembahasan}

Kegiatan yang dilaksanakan dengan cara daring melalui platform Zoom berjalan dengan baik dan lancar. Pertemuan tatap muka secara virtual dengan metode brainstorming dan ceramah dilanjutkan tanya jawab diakhir kegiatan. Tidak ada hambatan yang berarti dalam kegiatan ini.

Kegiatan seminar Strategi Low Cost Digital Marketing di Masa Pandemi yang sudah dilaksanakan diharapkan dapat menambah pengetahuan, keterampilan dalam pemanfaatan Digital Marketing di masa Pandemi yang efektif dan minim pendanaan.

Berbagai pertanyaan diajukan secara antusias oleh para peserta dalam sesi tanya jawab. Secara garis besar inti dari pertanyaan para peserta adalah:

1. Untuk pengguna Digital Marketing pemula, hal apa saja yang perlu dilakukan pada awal pengguna yang baru terjun ke dalam dunia Digital Marketing. 
2. Strategi apa yang terbaik dalam memilih platform yang digunakan dalam Digital Marketing yang tidak banyak memakan budget namun efektif.

3. Bagaimana mengatur strategi pemasaran agar dapat menyelamatkan bisnis dimasa pandemi.

Diharapkan agar kegiatan Pengabdian kepada Masyarakat ini dapat bermanfaat untuk peserta selaku pemilik UMKM di Kecamatan Bojongloa Kidul. Faktor pendorong yang mempengaruhi kelancaran pelaksanaan kegiatan ini adalah keinginan peserta untuk memperoleh pengetahuan dan keterampilan dalam Strategi Low Cost Digital Marketing di Masa Pandemi.

\section{Bab V Kesimpulan dan Saran}

\section{Kesimpulan}

Berdasarkan hasil kegiatan seminar Strategi Low Cost Digital Marketing di Masa Pandemi menunjukkan bahwa pelaku UMKM di Kecamatan Bojongloa Kidul Kota Bandung mampu memahami strategi tentang Strategi Low Cost Digital Marketing di Masa Pandemi. Kegiatan ini disampaikan melalui metode ceramah dan tanya jawab.

\section{Saran}

Berdasarkan hasil kegiatan yang telah dilakukan beberapa saran yang dapat diajukan adalah kepada para peserta kegiatan ini agar dapat menerapkan ilmu-ilmu yang didapat pada kegiatan yang diikuti dilingkungan masyarakat sehingga informasi yang disampaikan bersifat baik dan berkualitas. Diharapkan dari pemahaman dan pengalaman peserta kegiatan ini dapat menyalurkan kembali ilmu yang didapat kepada pelaku UMKM lain sehingga para pelaku UMKM dapat terus berjalan selama masa pandemi dan mampu mendorong Kembali perekonomian negara dengan menerapkan Strategi Low Cost Digital Marketing di Masa Pandemi dalam memasarkan usahanya selama masa pandemi Covid-19.

\section{DAFTAR PUSTAKA}

[1] Kasali, Rhenald. 2001. "Membidik Pasar Indonesia”. Jakarta: Gramedia Pustaka Utama.

[2] Morissan. 2010. "Komunikasi Pemasaran Terpadu”. Jakarta: Kencana.

[3] Morissan. 2010. "Komunikasi Pemasaran Terpadu". Jakarta: Kencana.

[4] Morissan. 2010. "Komunikasi Pemasaran Terpadu". Jakarta: Kencana. 